\title{
Capacitação em boas práticas de manipulação de alimentos em um restaurante universitário: relato de uma experiência de extensáo
}

Training in good food handling practices in a university restaurant: report of an extension experience

\section{RESUMO}

Os alimentos são essenciais para o fornecimento de energia e aporte nutricional para atender às necessidades fisiológicas dos seres humanos. No entanto, é necessário garantir a inocuidade dos alimentos e a segurança ao consumidor. Ambas são conseguidas pela utilização das ferramentas das Boas Práticas de Fabricação (BPF) e Boas Práticas de Higiene (BPH), empregadas durante as etapas de manipulação dos alimentos. Este trabalho relata a experiência de um projeto de extensão universitária, cujo objetivo foi promover treinamentos de capacitação aos manipuladores de alimentos pertencentes ao restaurante universitário do Campus 1 do Centro Federal de Educaçáo Tecnológica de Minas Gerais (CEFET-MG), do município de Belo Horizonte-MG. A equipe do projeto foi formada por duas professoras da instituição e duas alunas. Os treinamentos permitiram que os 45 manipuladores fossem capacitados a manipular os alimentos utilizando os preceitos de higiene e segurança alimentar. O projeto também contribuiu para a formaçáo das alunas, cujas experiências vivenciadas as permitiram conhecer a realidade de uma cozinha industrial, bem como de um ambiente de trabalho. Apesar do êxito do programa de capacitaçáo, considerou-se que treinamentos mais frequentes devem ser realizados para que essas açóes mantenham os resultados alcançados.

Palavras-chave: Treinamento. Manipulação de alimentos. Boas práticas de fabricação. Higiene alimentar.

\section{ABSTRACT}

Food is essential for the provision of energy and nutritional support to the physiological needs of humans. However, it is necessary to ensure food and consumer safety. Both can be achieved by the use of Good Manufacturing Practices (GMP) and Good Hygiene Practice (GMP) tools, during food handling stages. This work reports the experience of a university extension project, which main objective was to promote training of food handlers who worked in the Campus 1 restaurant
Mariana de Lourdes Almeida Vieira

Doutora em Microbiologia pela Universidade Federal de Minas Gerais, Brasil; professora efetiva do

Departamento de Química do Centro Federal de Educação Tecnológica de Minas Gerais, Brasil (marianalavieira@ yahoo.com.br).

Flávia Augusta Guilherme Gonçalves Rezende

Doutora em Ciência de Alimentos pela Universidade Federal de Minas Gerais, Brasil; professora do Centro Federal de Educação Tecnológica de Minas Gerais, Brasil (flaviaggoncalves@gmail.com). 
of the Federal Center of Technological Education of Minas Gerais (CEFET-MG), in the city of Belo Horizonte, State of Minas Gerais, Brazil. The project team was formed by two teachers and two students of the institution. The training allowed the 45 handlers to be able to handle food using hygiene and food safety precepts. The project also contributed to the training of the students, whose experiences have allowed to know the reality of an industrial kitchen, as well as the work environment. Despite the success of the training program, it was considered that more frequent trainings should be carried out in order to maintain the achieved results.

Keywords: Training. Food handling. Good manufacturing practices. Food hygiene.

\section{INTRODUÇÃO}

A alimentação deve apresentar qualidade higiênico-sanitária satisfatória e adequado teor nutricional para suprir as necessidades fisiológicas dos seres humanos. Qualidade, segurança alimentar, higiene e confiabilidade são aspectos determinantes para a oferta de produtos alimentícios em restaurantes e em outros estabelecimentos que os comercializam e/ou produzem. A baixa qualidade de um produto alimentício, além de diminuir a credibilidade do estabelecimento que o fornece, pode colocar a saúde dos consumidores em risco (FORSYTHE, 2002).

O aumento da produção e comercialização de alimentos gera uma preocupação inevitável com a segurança alimentar, uma vez que podem ser veiculadores de doenças transmitidas por alimentos (DTAs), representando risco à saúde pública. Nesse contexto, o conceito de qualidade engloba não somente características como aroma, sabor, textura e aparência dos produtos, mas como também o cuidado em se produzir e comercializar alimentos que não sejam veiculadores de DTAs (SILVA et al., 2011). Um alimento pode ser considerado seguro quando não oferece perigo à saúde do consumidor. Esses perigos podem ser biológicos (bactérias, vírus, fungos, parasitas, dentre outros), químicos (produtos químicos, inseticidas, dentre outros) e/ou físicos (materiais como pregos, vidros, plásticos, dentre outros) (ELIAS; MADRONA, 2008). 
A segurança dos alimentos pode ser garantida por meio de estratégias que incluem o controle do fornecedor e das matérias-primas, controle do processo, aplicação de Boas Práticas de Fabricação (BPF) e Boas Práticas de Higiene $(\mathrm{BPH})$ durante as etapas da produção e manipulação dos alimentos, além da utilização do sistema de Análise de Perigos e Pontos Críticos de Controle (APPCC) (MINNAERT; FREITAS, 2010).

Segundo Costa et al. (2012) as BPF e a manipulação de alimentos são um conjunto de princípios que regem o correto manuseio dos alimentos, abrangendo desde a matéria-prima até o produto final. Trata-se de normas e procedimentos utilizados para se alcançar um determinado padráo de qualidade de um produto e/ou serviço na área de alimentos, cuja efetividade deve ser continuamente avaliada. As BPF são estabelecidas pela legislação vigente e devem ser sistematicamente seguidas pelos estabelecimentos que manipulam e comercializam alimentos.

A ocorrência de DTAs pode ser evitada ou ter os riscos reduzidos por meio da implementação de programas e práticas educativas que visem à qualidade e segurança dos alimentos, pautadas nas boas práticas de higiene e manipulação. No entanto, frequentemente, verificase que há, entre os manipuladores de alimentos, uma carência de informaçóes sobre BPF, higiene e segurança alimentar (SOARES; CANTOS, 2005).

De acordo com Andreotti (2003), são considerados “manipuladores de alimentos" todas as pessoas que entram em contato com parte ou com o todo da produção de alimentos, incluindo os que colhem, beneficiam, armazenam, transportam, processam ou preparam, compreendendo, nesse caso, os colaboradores presentes em estabelecimentos como os restaurantes. Silva et al. (2006) destacam ainda que programas para treinamento de manipuladores de alimentos devem ser criados e implementados nesse tipo de estabelecimento, uma vez que essa é uma das medidas capazes de assegurar o fornecimento de alimentos seguros à comunidade, estando de acordo com as BPF.

Tokuc et al. (2015) afirmam que a capacitação profissional de manipuladores de alimentos deve consistir no treinamento dos colaboradores quanto aos principais contaminantes alimentares, doenças transmitidas por alimentos (DTAs), manipulação higiênica 
dos alimentos, higiene pessoal e operacional e BPF, entre outros tópicos de conteúdo de relevância para a prática desses profissionais. Segundo esses autores, uma capacitação insuficiente ou inadequada representa uma ameaça à segurança dos alimentos preparados e, consequentemente, à sua adequação para o consumo.

Nesse contexto, o presente relato tem como cenário a experiência de um projeto de extensão universitária que teve como objetivo principal promover treinamentos e cursos de capacitação aos manipuladores de alimentos pertencentes ao restaurante universitário do Campus 1 do Centro Federal de Educação Tecnológica de Minas Gerais (CEFETMG), do município de Belo Horizonte-MG, por meio de açóes educativas executadas na própria instituição. Essas atividades visaram oferecer informaçóes pertinentes sobre os diversos temas em BPF, higiene e segurança alimentar, possibilitando aos colaboradores uma reflexão sobre sua prática diária e buscando promover mudanças em seus hábitos de trabalho. Essas açóes tiveram também a finalidade de promover a importante interlocução entre o conhecimento científico e a prática, no que diz respeito às técnicas adequadas para o preparo de alimentos e refeiçóes com qualidade e segurança.

\section{DESCRIÇÃO DAS ATIVIDADES}

O presente trabalho de extensão foi desenvolvido em quatro etapas, no período de março de 2015 a outubro de 2016. O projeto foi realizado em colaboração com a equipe de funcionários do Restaurante Universitário do Campus 1 do CEFET-MG, envolvendo dois nutricionistas e 45 colaboradores (manipuladores de alimentos), além de dois alunos bolsistas, sendo que um cursava o terceiro ano do curso técnico em Química e outro o $3^{\circ}$ período do curso de graduação em Química Tecnológica, ambos da mesma instituiçáo. $\mathrm{O}$ projeto contou ainda com a coordenação de duas professoras com formação nas áreas de Engenharia de Alimentos e Microbiologia.

$\mathrm{Na}$ primeira etapa, realizou-se uma pesquisa exploratória com relação às condiçôes higiênico-sanitárias e cumprimento das BPF no manuseio dos alimentos e preparo das refeiçóes servidas, no restaurante, diariamente, à comunidade local. Em seguida, foram realizadas entrevistas com os nutricionistas e manipuladores de 
alimentos, a fim de conhecer melhor o ambiente de trabalho e as condiçôes de preparo e manipulação das refeiçôes até o local onde seriam servidas. Foram também levantados, por meio de entrevistas, dados a respeito dos treinamentos e programas de capacitação já existentes no local, além da participação prévia dos colaboradores nessas atividades. Adicionalmente, foram realizadas visitas técnicas ao local para observação dos hábitos e atitudes dos colaboradores, além das condiçóes do ambiente e da forma de manuseio dos alimentos a serem preparados.

$\mathrm{Na}$ segunda etapa, a partir dos dados coletados com a pesquisa exploratória, realizou-se um levantamento das principais não conformidades observadas durante as visitas técnicas e entrevistas. Esse levantamento foi utilizado como subsídio para a produção do material didático e programação dos cursos de capacitação e treinamentos que mais se adequariam à realidade do local. Foi realizado também um levantamento de quais temas necessitariam ser abordados, além da constatação de que todos os colaboradores participariam do programa de treinamento a ser proposto.

A terceira etapa consistiu na programação dos treinamentos e elaboração dos materiais didáticos a serem utilizados. A metodologia compreendeu o oferecimento de oficinas e dinâmicas de orientação aos colaboradores por meio da elaboração de materiais informativos impressos (incluindo painéis e folhetos), apresentação de vídeos, debate oral, aulas expositivas dialógicas, além da realização de atividades práticas no Laboratório de Microbiologia da instituição. Os materiais utilizados foram elaborados pelos alunos bolsistas do projeto supervisionados pelos professores coordenadores. Foi confeccionado ainda material impresso (apostila) sobre os temas de BPF, higiene e segurança alimentar que foi cedido ao restaurante a fim de auxiliar em futuros treinamentos ou para a consulta, pelos colaboradores, sempre que necessário.

$\mathrm{Na}$ última etapa, após a realização dos treinamentos, os participantes e todos os envolvidos com as atividades propostas puderam avaliar os impactos delas em sua prática diária. 


\section{DISCUSSÃO}

Após a realização de visitas técnicas ao restaurante e entrevistas com os profissionais (manipuladores de alimentos e nutricionistas), constatouse que o estabelecimento servia duas refeiçóes por dia, almoço e jantar, para toda a comunidade universitária. Foi relatado, nas reunióes realizadas, que todos os colaboradores do restaurante, ao serem admitidos, recebiam um treinamento básico sobre BPF e segurança alimentar, além de aprenderem as principais técnicas necessárias para o preparo e manipulaçáo dos alimentos. No entanto, esses treinamentos necessitavam de ser realizados novamente e com maior frequência, uma vez que alguns conceitos ainda não haviam sido incorporados à prática diária dos manipuladores. Alguns colaboradores relataram ainda, durante as entrevistas, não possuírem o conhecimento técnico necessário sobre a manipulação de alimentos conforme as Boas Práticas de Fabricação (BPF), o que configuraria um risco ao consumidor. Nesse contexto, a elaboração de cursos de BPF específicos para a realidade desse estabelecimento se fazia necessária.

Após levantamento das principais não conformidades observadas durante a pesquisa exploratória, iniciou-se a elaboração de materiais educativos e treinamentos que contemplassem os seguintes temas: $\mathrm{BPF}$; perigos físicos, químicos e biológicos em alimentos; microbiologia de alimentos; principais DTAs causadas por microrganismos; manipulação segura de alimentos; procedimentos de higiene e limpeza; higiene pessoal e saúde do trabalhador; controle de pragas; procedimentos operacionais padrão e legislação sanitária.

As atividades prévias ao treinamento incluíram a elaboração de materiais didáticos como uma apostila e aulas teóricas, com base na pesquisa em artigos científicos, legislação sanitária e livros da área. As apostilas foram confeccionadas para os participantes acompanharem as aulas e obterem uma melhor fixação do conteúdo, além de servirem como material de consulta após o treinamento. As aulas teóricas foram desenvolvidas em power point, servindo como apoio às explicaçôes e dinâmicas realizadas durante o treinamento. $\mathrm{O}$ treinamento contemplou aulas teóricas expositivas com o auxílio de recursos de multimídia e ainda a complementação do conteúdo com aulas práticas, realizadas no laboratório de Microbiologia do CEFETMG. Também foram entregues aos participantes fôlderes contendo 
o conteúdo das apresentaçóes, além do certificado de participação.

Durante o curso foram realizadas duas dinâmicas para mostrar a importância e a forma correta de higienização das mãos, apresentação de vídeos e fotos obtidas de situaçôes reais nas quais os princípios de BPF não eram aplicados durante a manipulação de alimentos (não conformidades). Um momento muito importante do treinamento foi a realização de uma dinâmica com o intuito de demonstrar o correto procedimento de higienização das mãos. Os bons hábitos de higiene e cuidados com a saúde pessoal diminuem os riscos de contaminação dos alimentos, tendo sido essa aula de suma importância. Foram abordadas as técnicas de higiene pessoal, mais especificamente de mãos, antebraços e unhas, explicando-se como fazer a limpeza e a antissepsia dos mesmos. A técnica foi realizada por todos os participantes, seguida por uma coleta, por meio de swab, de microrganismos presentes nas máos antes e após a correta higienização. Também foram realizadas coletas de amostras do cabelo e do rosto, com o auxílio de um swab, com o intuito de demonstrar a presença de possíveis contaminantes microbiológicos nessas áreas do corpo. Em todas as placas incubadas verificou-se o crescimento de colônias de bactérias, leveduras e fungos filamentosos provenientes das amostras coletadas. Observou-se ainda uma redução significativa no número de colônias nas placas coletadas após correta higienizaçáo das mãos, indicando que essa é uma medida eficaz para controle da contaminaçáo microbiana. Por fim, foram disponibilizadas placas de Petri (previamente preparadas, incubadas e lacradas em laboratório) para visualização de microrganismos inoculados a partir de mãos sujas, mãos lavadas com água e sabão e máos higienizadas com álcool a $70 \% \mathrm{p} / \mathrm{v}$.

Segundo Bertolo et al. (2016), a educação e a realização de treinamentos constantes são as formas mais eficientes para se melhorar a qualidade da alimentação servida, uma vez que criam um conjunto de meios e processos nos quais o colaborador é ensinado e aperfeiçoado na execução de determinada tarefa. Todos os cursos foram ministrados na própria instituição, com uma carga-horária de oito horas. Ao final de cada curso, foi realizado um debate para sanar as possíveis dúvidas dos participantes. Na última etapa do projeto, os treinamentos realizados foram avaliados pelos próprios participantes, que passaram a adotar os conceitos trabalhados em sua prática diária. 
Heidemann et al. (2009) consideram que o treinamento envolve transmissão de conhecimentos específicos relativos ao trabalho, atitudes frente a aspectos da organização, da tarefa e do ambiente, e o desenvolvimento de habilidades. Quando aplicado aos serviços que envolvem a manipulação de alimentos, reduz o número de casos de surtos alimentares, conduzindo a uma consequente diminuição nos gastos com saúde pública e melhor qualidade de vida da população (PARK et al., 2010). Além disso, muitas vezes é necessária a realização de treinamentos contínuos, de forma a reforçar mensagens e algumas técnicas de trabalho. Campos et al. (2004), em estudo sobre capacitação profissional em empresas paulistas, verificaram que o treinamento vem sendo utilizado com o objetivo geral de desenvolver pessoas, tanto na aprendizagem de novas habilidades quanto na ampliação daquelas já existentes, o que foi também constatado em nossa atividade de extensão.

O projeto de extensão universitária também proporcionou aos alunos bolsistas a oportunidade de interagir com a comunidade e ter contato com os problemas emergentes, integrando o conhecimento teórico às vivências diárias do estabelecimento. Os alunos receberam treinamentos prévios pelos coordenadores do projeto, com orientaçôes relacionadas à saúde e segurança dos alimentos, bem como sobre os demais temas abordados nos treinamentos. De acordo com Pereira et al. (2015), a parceria entre a universidade e a comunidade contribui para o desenvolvimento de conceitos e práticas voltadas à saúde e possibilita à instituição exercer seu papel como agente social modificador dentro do seu âmbito de atuação. Além disso, possui um papel essencial na formação de recursos humanos, por abranger dimensôes acadêmicas, sociais e econômicas. Nesse contexto, as atividades desenvolvidas atenderam ao objetivo proposto pelo projeto de extensão universitária, de estender informaçóes pertinentes sobre os diversos temas em BPF, higiene e segurança alimentar, possibilitando aos colaboradores do restaurante universitário uma reflexão sobre sua prática diária e promovendo mudanças em seus hábitos de trabalho.

\section{CONSIDERAÇÕES FINAIS}

Por meio de um programa de treinamentos e capacitação, a realização desse projeto de extensão universitária constituiu uma importante 
estratégia para disponibilizar informaçóes relevantes sobre BPF, higiene e segurança alimentar aos colaboradores do restaurante do CEFET-MG. Além disso, o projeto proporcionou aos alunos bolsistas de graduação e de ensino técnico experiências extracurriculares e a oportunidade de interagir com a comunidade, integrando teoria à prática.

Com base no exposto, pôde-se ainda perceber que os cursos e treinamentos oferecidos foram eficientes para melhorar as condiçóes higiênico-sanitárias do restaurante universitário, bem como aperfeiçoar a prática de trabalho dos manipuladores de alimentos. No entanto, considera-se que novos treinamentos devem ser realizados com uma maior periodicidade, de forma que tais conceitos sejam sempre revistos e reforçados, no intuito de que essas ações mantenham os resultados alcançados.

\section{REFERÊNCIAS}

ANDREOTTI, A. et al. Importância do treinamento para manipuladores de alimentos em relação à higiene pessoal. Iniciação Científica Cesumar, Maringá, v. 5, n. 1, p. 29-33, jan./jun. 2003,

BERTOLO, A. P. et al. Experiência do uso das boas práticas de fabricação para melhoria das condições higiênico-sanitárias da Feira do Agricultor de Laranjeiras do Sul-PR. Revista Brasileira de Extensão Universitária, Chapecó, v. 7, n. 1, jan/jun. 2016, p. 51-57. doi: https://doi.org/10.24317/2358-0399.\%25Yv7i1.3101.

CAMPOS, K. C. L. et al. Avaliação do sistema de treinamento e desenvolvimento em empresas paulistas de médio e grande porte. Psicologia: Reflexão e Crítica, Porto Alegre, v. 17, n. 3, p. 435-446, 2004. doi: https://doi.org/10.1590/S0102-79722004000300015

COSTA T. S. et al. Oficinas de boas práticas de fabricação: construindo estratégias para garantir a segurança alimentar. Brazilian Journal of Food Technology, Campinas, p. 64-68, maio 2012. doi: http:// dx.doi.org/10.1590/S1981-67232012005000037.

ELIAS, A. H.; MADRONA, G. S. Avaliação de uma indústria produtora de embutidos cárneos quanto à higiene e legislação vigente 
no brasil. Revista Brasileira de Tecnologia Agroindustrial, Ponta Grossa, v. 2, n. 2, p. 71-81, 2008. doi: https://dx.doi.org/10.3895/ S1981-36862008000200007.

FORSYTHE, S. J. Microbiologia da segurança alimentar. Porto Alegre: Artmed, 2002, 341 p.

HEIDEMANN, R. et al. Nível de conhecimento dos trabalhadores de indústrias de produtos suínos sobre a manipulação higiênica dos alimentos. Revista Higiene Alimentar, São Paulo, v. 23, n. 174-175, p.47-51, 2009.

MINNAERT, A. C. S. T.; FREITAS, M. C. S. Práticas de higiene em uma feira livre da cidade de Salvador (BA). Ciência e Saúde Coletiva, Rio de Janeiro, v. 15, n. 1, p. 1607-1614, 2010. doi: https://dx.doi. org/10.1590/S1413-81232010000700072

PARK, S. H. et al. Evaluation of the food safety training for food handlers in restaurant operations. Nutrition Research and Practice, v. 4, n. 1, p. 58-68, 2010. doi: https://dx.doi.org/10.4162/ nrp.2010.4.1.58.

PEREIRA, T. L. et al. Eficácia de treinamentos sobre as boas praticas de fabricação no setor agroalimentar. Archives of Veterinary Science, Curitiba, v. 20, n. 3, p. 30-38, 2015. doi: http://dx.doi.org/10.5380/ avs.v20i3.38393.

SILVA, A. B. P. et al. O controle microbiológico dos manipuladores, como indicativo da necessidade de medidas corretivas higiênicosanitárias, em restaurante comercial. Revista Higiene Alimentar, São Paulo, v. 20, n. 145, p. 36-39, out. 2006.

SILVA, C. B. G.; ALMEIDA, F. Q. A. Qualidade na produção de refeiçôes de uma unidade de alimentação e nutrição (UAN). Revista Simbio-Logias, Botucatu, v. 4, n. 6, p. 155-162, dez. 2011.

SOARES, B.; CANTOS G. A. Qualidade parasitológica e condiçóes higiênico-sanitárias de hortaliças comercializadas na cidade de Florianópolis, Santa Catarina, Brasil. Revista Brasileira de Epidemiologia, São Paulo, v. 8, n. 4, p. 377-388, 2005. doi: https:// dx.doi.org/10.1590/S1415-790X2005000400006.

TOKUC, B. et al. Knowledge, attitudes and self-reported practices 
of food service staff regarding food hygiene in Edirne, Turkey. Food Control, v. 20, p. 565-568, 2015. doi: https://dx.doi.org/10.1016/j. foodcont.2008.08.013.

Submetido em 13 de julho de 2018.

Aprovado em 21 de agosto de 2018. 